\title{
I-O Practice in Action: Solving the Leadership Potential Identification Challenge in Organizations
}

Rob Silzer

HR Assessment \& Development, Inc., and Baruch, Graduate Center, City University of New York

Allan H. Church and Christopher T. Rotolo

PepsiCo, Inc.

John C. Scott

APTMetrics, Inc.

In 2008, we saw an emerging business need to accurately identify and develop individuals early in their careers who have the potential to be effective leaders in later organizational positions. We decided early on to take a comprehensive and systematic approach to the challenge in order to build effective solutions with real organizational impact that are sustainable over time. We knew that this was a complex problem and that there was little agreement in industrial-organizational (I-O) psychology on how to approach this critical business need and what approaches would be most effective. Since then, we moved through the following process stages to arrive at effective solutions that are now being used in numerous organizations.

1. Defining the business need

2. Determining the current state of leadership potential

3. Reviewing relevant research and practice

4. Building a comprehensive model of leadership potential

5. Developing and implementing tools and programs that bring the model to life

6. Evaluating outcomes and determining organizational impact

We think that our process provides a good example of how I-O psychology practitioners can address real business needs with an effective process

Rob Silzer, HR Assessment \& Development, Inc., New York, New York, and Department of Psychology, Baruch, Graduate Center, City University of New York; Allan H. Church and Christopher T. Rotolo, PepsiCo, Inc., Purchase, New York; John C. Scott, APTMetrics, Inc., Darien, Connecticut.

Correspondence concerning this article should be addressed to Rob Silzer, HR Assessment \& Development, Inc., 14 West 11th Street, New York, NY 10011. E-mail: robsilzer@prodigy.net 
and impactful solutions. We want to share our experience and hope that others can benefit from the process we used as well as the models and approaches we developed.

\section{Defining the Business Need}

Business organizations have long been interested in effectively selecting and developing leaders. More recently, over the last 20 years, senior business leaders, investors, and boards of directors have increased their attention and concerns regarding the quality of organizational leadership (Charan, Carey, \& Useem, 2014).

The impact of globalization, the increasing demand for strong, effective leaders, and the competition for talent have placed a premium on not just having a strong leadership team for the current organization but also ensuring that there is a strong leadership talent pipeline for future organizational needs. This has led organizations to rethink the effectiveness of their internal leadership development efforts and the degree to which they need to buy versus continue to identify and build their talent from within (Joyce, 2010). At the same time, talent management has become a new strategic direction and organizing framework for human resources (HR) departments. Silzer and Dowell (2010) have argued that identifying potential talent is an important component of an effective talent management system. Silzer and Church go further and state that "the singular ability to define and identify that elusive variable known as potential in an individual or group of individuals is considered a competitive advantage in the marketplace" (Silzer \& Church, 2009a, p. 377) and suggest that identifying potential leadership talent is a critical strategic objective for an organization (Church \& Silzer, 2014; Silzer \& Church, 2009a).

This put demands on I-O psychology practitioners to help organizations identify individuals early in their careers who have the potential to be effective leaders in the future. The business need was to ensure that future leadership talent needs in the organization would be met by identifying and developing individuals early in their career who had leadership potential.

\section{Determining the Current State of Leadership Potential}

The next step in our process was to determine the current state of leadership potential and how it was being defined and measured in organizations today. To help sort this out, Silzer and Church (2010) conducted a survey of the high potential practices in 20 major organizations. We asked about definitions, identification factors, assessment tools and techniques, development programs, and so forth. The results gave us considerable insight into current organizational practices related to high potential talent. The most common definitions are reported in Silzer and Church (2010). 
Based on the survey results and our own practice experience, we defined individuals with leadership potential as those "individuals early in their careers who demonstrate the abilities, skills, characteristics and behaviors that are reliable predictors of later leadership success" (Church \& Silzer, 2014, p. 52). Definitions offered since by other scholars and practitioners are consistent with this approach, though they may emphasize certain aspects over others, such as skills and abilities, "how likely an individual is to learn and grow quickly as a leader" (Paese, Smith, \& Byham, 2016, p. 90), outcomes, or "the ability to perform exceptionally well (at work for a reasonable amount of time) for their own benefit and that of the organization" (MacRae \& Furnham, 2014, p. 17). The common denominator, however, is that we are predicting future leadership capability not current performance, which has often been a source of confusion in the academic literature in this area (Silzer \& Church, 2009a).

\section{Reviewing Relevant Research and Practice}

Next, we launched into a major review of current practices, models, and research studies. We discovered that there was limited published, organizationbased research on identifying early career indicators of later leadership effectiveness. As noted, most of the published research on leadership focused on finding variables that correlated with concurrent leadership effectiveness. In the past, this has been the dominant approach in the leadership research. But we were interested in finding longitudinal predictive research. We did find some research that identified genetic, childhood, adolescent, and early adult indicators that predicted near term leadership role occupancy or leadership emergence (Silzer \& Borman, in press). The constraints from this literature were that the early life predictors might have limited usefulness for organizations, and the criteria of role occupancy or leadership emergence were not sufficient to predict later leadership effectiveness. After all, we were not interested in trying to predict who would later merely occupy leader roles but rather were interested in trying to predict who would be highly effective as a future leader.

We also scanned professional publications and practice for all available predictors, studies, and models that focused on identifying high potential talent. We summarized the available research and the current state of models of potential, and we provided a broad integration for understanding the critical components of potential (Silzer \& Church, 2009a, 2009b). The models we focused on were typically well supported by research from leading I-O psychology practice consulting firms. (Full reviews of current organizational practices, findings, and models in I-O practice and relevant empirical research can be found in Silzer \& Church, 2009a, 2010, and Silzer \& Borman, in press.) 
In our review, we discovered patterns of variables that looked similar coming from widely different sources. We realized that there might be an emerging alignment on a core set of variables that predicted future leadership effectiveness. This gave us hope that we might find a common core set of individual difference variables as useful predictors of potential, which could provide a useful framework to guide I-O practice and research moving forward in this area.

\section{Building a Comprehensive Model of Leadership Potential}

Based on our reviews and experience, we set out to build a new model of leadership potential predictors. Our resulting model, the Leadership Potential BluePrint (BluePrint), is based on

(a) a thorough review of relevant theory, practice, and research;

(b) data and high potential frameworks collected from leading consulting firms;

(c) recent benchmark studies of high potential practices in "top development" companies;

(d) internal models, tools, and practices from highly regarded organizations in talent management as well as learning and development; and

(e) extensive internal and external professional experience in the assessment, staffing, and development of leaders and executives.

Our review suggested that there was a naturally emerging clustering of the common predictor variables. The BluePrint identifies a new structure for leadership potential that involves three types of predictor dimensions of potential: foundational, growth, and career dimensions (Silzer \& Church, 2009a, 2009b).

Foundational dimensions are fairly stable over time and difficult to change; in adulthood they are relatively consistent across situations, experiences, and time. They are unlikely to develop or change much without considerable intervention and support from others. Typical examples are cognitive abilities and many personality variables, including interpersonal and social skills.

Growth dimensions facilitate or hinder a person's growth and development. They are intervening variables to learning and can be useful indicators of whether a person will further develop and learn additional skills. They can be somewhat consistent and stable across situations, but they might be more manifest and might strengthen when a person has strong personal interests in an area, has an opportunity to learn more in those areas of interest, and has a supportive, encouraging environment.

Career dimensions of potential are typically early indicators of the later end-state skills needed in a career. The specific behavioral dimensions of 


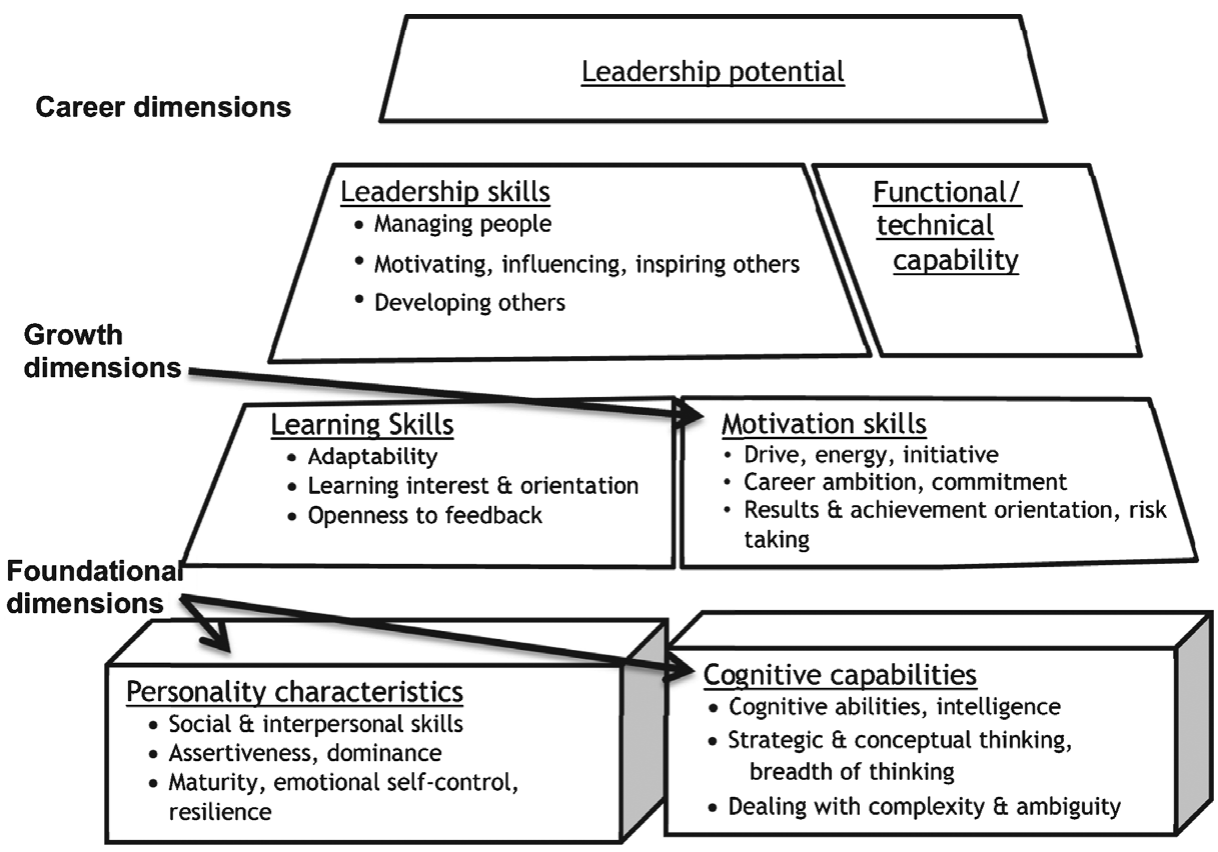

Figure 1. Leadership Potential BluePrint.

Adapted from "The Pearls and Perils of Identifying Potential," by R. Silzer and A. H. Church, 2009a, Industrial and Organizational Psychology Journal: Perspectives on Science and Practice, 2, p. 401. Copyright 2009 by Society for Industrial and Organizational Psychology.

potential may depend on the individual career path being considered and on the answer to this question: Potential for What?

The Leadership Potential BluePrint is an integrated framework that emerged from our review of related theory, science, and practice (see Figure 1). In our view, the BluePrint includes the critical building blocks of leadership potential, is comprehensive, and is generalizable across most organizations. As Church and Silzer (2014) have pointed out "the BluePrint is specifically intended to help senior leaders, managers, human resource professionals, and chief talent management officers better understand and make critical decisions regarding high potential identification and leadership development" (p. 51).

The BluePrint is gaining traction in the business landscape as well and is currently the underlying framework for integrated leadership potential assessment and development efforts at several major corporations with strong talent management functions such as PepsiCo, Eli Lilly, and Citibank (Church \& Silzer, 2014). It also has been cited as part of the underlying basis of other firms' consulting approaches (e.g., Aon-Hewitt, 2013), as well as scholar-practitioner models and reviews of potential (e.g., MacRae \& 
Furnham, 2014; Piip \& Harris, 2014). In addition, it was recently featured in a white paper on leadership development (Dugan \& O'Shea, 2014) published jointly by the Society for Industrial Organizational Psychology (SIOP) and the Society for Human Resource Management (SHRM). Finally, recent research with 80 large, highly respected companies recognized for their strong talent management functions (Church, Rotolo, Ginther, \& Levine, 2015) suggests that the BluePrint represents a comprehensive conceptual framework encompassing what these organizations are using today internally to assess for high potentials among their leadership populations. Although there are other models of potential available to organizations in the consulting marketplace, the BluePrint is one of the few that is grounded in a comprehensive review of the academic and applied literature as well as practice in I-O psychology.

\section{Developing and Implementing Tools and Programs That Bring the Model to Life}

The BluePrint provides the foundation and conceptual framework for tailoring and implementing leadership identification and assessment efforts across organizational levels. Although the BluePrint is somewhat "prescriptive" in defining potential, the actual configuration and weighting of the assessment tools can be readily tailored to the organization, its competency framework, and targeted leadership roles at multiple levels. We have found that the BluePrint resonates quite well with senior leadership by helping them to understand the elements of leadership potential and the logic behind its measurement.

As with any high potential assessment program, it is important to first understand the leadership requirements of the targeted roles against which potential is to be assessed. This is typically accomplished through a formal job analysis or competency modeling effort. The leadership competency model (which populates the BluePrint career dimension) is ideally designed to enable a clear view of career progression and provide a common set of expectations for leadership positions across the organization (i.e., business sectors, functions, and regions). The goal here is to populate the BluePrint by developing and validating leadership competencies and knowledge, skills, abilities, and other characteristics (KSAOs) that contribute to success as a leader. This information can then be used to design and validate a suite of assessments to accurately evaluate leadership potential.

Here is an application example: To illustrate how the BluePrint can be used as the underlying structure for a large-scale leadership assessment and development framework, let us turn to the case of PepsiCo's Leadership Assessment and Development (LeAD) program architecture. Several years ago, under the direction of Cynthia Trudell, PepsiCo's Executive Vice President, 
Human Resources, and Chief Human Resources Officer, the internal team of I-O psychologists in the global talent function embarked on a journey to enhance the level of objectivity, consistency, rigor, and impact of their talent management processes at a total systems level. Although this effort resulted in a number of significant changes in and realignment of the HR function, one of the key drivers and enablers of this shift was the introduction of a fully integrated, evidence-based assessment and development process. This process, called the LeAD program, was designed specifically to address the key question of how to identify the best and brightest talent across multiple levels in the organization (from early career to senior executive) and ensure that these individuals achieve their fullest potential.

Although many organizations take advantage of assessment and feedback tools, what makes PepsiCo's LeAD approach different is that it is grounded in two important constructs. The first is the Leadership Potential BluePrint, which focuses on the underlying nature of potential and Potential for What?, and the second is the organization's future focused Leadership Effectiveness Framework (LEF) that articulates the competencies and unique set of behaviors needed at different levels of career progression for the long-term success of the organization. Based on input and guidance from the $\mathrm{CEO}$, the board of directors, key internal stakeholders, and external thought leaders, the LEF ensures a common language and profile of leadership success at different levels of career progression.

Unlike many other leadership models, PepsiCo's approach is focused squarely on what will be needed to be successful in the future (e.g., being a sophisticated strategist, delivering results through collaborative relationships with others across the matrix, and demonstrating "cultural savoir faire") rather than on what has made leaders successful today. Although elements of the BluePrint differ in their ability to be directly addressed through development efforts (Church, 2014; Silzer \& Church, 2009a), by integrating the two designs, the feedback is provided in a behavioral framework, which enables maximum developmental impact for the program participants (e.g., rather than just report on a person's cognitive ability, the focus for the participant is on his or her strategic thinking and decision making). By integrating the BluePrint with the LEF, the organization is leaning forward in ensuring a holistic platform for developing leaders at all levels.

PepsiCo's LeAD program takes this approach by offering a suite of assessment and development tools throughout the employee lifecycle. Following the leadership pipeline construct (Charan, Drotter, \& Noel, 2001), PepsiCo has structured the approach according to four key "checkpoints" targeted at different stages or key transition points (see Table 1).

The underlying constructs measured by LeAD using the BluePrint and LEF are the same across all levels of the organization, which is critical for 
Table 1. PepsiCo LeAD Program Architecture

\begin{tabular}{|c|c|c|c|}
\hline Program & Target audience & $\begin{array}{c}\text { Program focus at this } \\
\text { organizational } \\
\text { level }\end{array}$ & $\begin{array}{c}\text { BluePrint content areas } \\
\text { emphasized }^{\mathrm{a}}\end{array}$ \\
\hline $\begin{array}{l}\text { Senior Leader } \\
\text { Development } \\
\text { Center } \\
\text { (Checkpoint 3) }\end{array}$ & - SVP+ & - Shape and refine & $\begin{array}{l}\text { - Leadership capability } \\
\text { - Functional breadth } \\
\text { - Learning ability } \\
\text { - Personality } \\
\text { - Cognitive (strategic) }\end{array}$ \\
\hline $\begin{array}{l}\text { Advanced Leader } \\
\text { Development } \\
\text { Center } \\
\text { (Checkpoint 2) }\end{array}$ & $\begin{array}{l}\text { - VP and senior } \\
\text { directors }\end{array}$ & $\begin{array}{l}\text { - Confirm and } \\
\text { develop }\end{array}$ & $\begin{array}{l}\text { - Leadership capability } \\
\text { - Functional breadth } \\
\text { - Learning ability } \\
\text { - Personality } \\
\text { - Cognitive (strategic) }\end{array}$ \\
\hline $\begin{array}{l}\text { Emerging Leader } \\
\text { Development } \\
\text { Center } \\
\text { (Checkpoint 1) }\end{array}$ & $\begin{array}{l}\text { - Directors and } \\
\text { managers }\end{array}$ & - Verify and stretch & $\begin{array}{l}\text { - Leadership capability } \\
\text { - Functional breadth } \\
\text { - Learning ability } \\
\text { - Personality } \\
\text { - Cognitive (conceptual) }\end{array}$ \\
\hline $\begin{array}{l}\text { Potential Leader } \\
\text { Development } \\
\text { Center } \\
\text { (Checkpoint 0) }\end{array}$ & $\begin{array}{l}\text { - Associate } \\
\text { managers and } \\
\text { early career } \\
\text { professionals }\end{array}$ & $\begin{array}{r}\text { - Identify and } \\
\text { differentiate }\end{array}$ & $\begin{array}{l}\text { - Leadership interests } \\
\text { - Motivation } \\
\text { - Learning ability } \\
\text { - Personality } \\
\text { - Cognitive (conceptual) }\end{array}$ \\
\hline
\end{tabular}

Note. LeAD $=$ Leadership Assessment and Development; SVP $=$ senior vice president; VP $=$ vice president.

${ }^{a}$ Each dimension of the BluePrint is assessed in all levels of LeAD but some are emphasized more than others.

ensuring a consistent and objective process; however, each checkpoint is designed for a specific purpose and addresses the question of Potential for What? slightly differently. This design results in a different level of emphasis being placed on the various dimensions of potential as well as different behavioral indicators of the leadership competencies for each of the checkpoints in the architecture. It also results in a somewhat different set of assessment tools and accompanying feedback and development rollout strategies being deployed at different levels, based on factors such as volume, cost, complexity, translations, impact to operations, internal availability of I-O practitioner resources, and political dynamics in the organization. Although the architecture of the LeAD framework was designed entirely internally, external partnerships with other I-O psychologists as well as prominent business school faculty were used to flesh out certain key aspects of the program (e.g., simulation design, validation, custom reporting) and continue to play a role in the ongoing effort. 
The purpose of the first checkpoint, called Potential Leader, is to identify and differentiate more junior talent. The emphasis here is heavily weighted on the foundational and growth capabilities of the BluePrint, as these are most relevant to general potential across any number of leadership roles this talent might one day fill. Thus the suite of tools used includes cognitive, personality, situational judgment, and biographical information (biodata). In short, this is how the organization finds its "diamonds in the rough." The program is offered globally to thousands of employees who meet basic thresholds of performance over time. In 2015 alone, the company put over 3,300 participants through Potential Leader. A category rating called the LIFT score (along with two strengths and two development areas for every participant) is one output of the process and represents a participant's advancement potential. The assessments for Potential Leader are all done online, and all participants receive developmental feedback and coaching from managers as part of the process. In line with PepsiCo's emphasis on self-awareness and growth, however, when employees are invited, they must elect to "opt in" to the program to declare their willingness to invest in their own development. Over $85 \%$ of those invited have chosen to do so. Of those who opted in, 97\% completed the full suite of assessment measures (Church \& Rotolo, 2016).

The second checkpoint, called Emerging Leader, is designed to verify and stretch participants to help them achieve their potential in larger leadership roles. This is a far more selective effort. Individuals chosen for this program have often but not always been identified as already showing signs of having high potential based on broad internal criteria (the vast majority are those seen as having some potential). Here, the measurement becomes more balanced, based on the BluePrint, including career elements (leadership and functional competencies) along with foundational and growth elements, as this is a tipping point for many midcareer professionals (e.g., those with manager to director titles in this organization). The process is again all done online and includes such tools as custom $360^{\circ}$ feedback, personality measures, a cognitive reasoning test, and a custom business simulation where participants act as a region president or sales leader. Custom feedback is provided via a partnership with external and internal staff; development planning from talent management, organization development (OD), and I-O professionals internally follows; and the results are integrated into individual career plans and learning and development efforts. Importantly, the results are also integrated as inputs into the company's formal People Planning efforts (Church \& Waclawski, 2010) as part of the employee's profile.

The third checkpoint is called Advanced Leader and is intended to confirm and develop the future leadership potential of those identified by the business to participate in the program. To support these goals, the program 
leverages assessment center methodology with a suite of in-person role plays and exercises along with the previously mentioned set of measurement tools (e.g., $360^{\circ}$ feedback, personality, cognitive, etc.). For this program, which is even more exclusive and externally resource intensive than the other programs, participant nominations are determined following the annual succession planning review. Again, a mix of high potentials and other talent across the enterprise are selected to participate in the program, although it is heavily weighted toward those seen as having significant career stretch. There is also the opportunity to nominate participants who need specific development support, to shore up longstanding but specific development gaps, given that these are executives of the corporation (e.g., senior directors and vice presidents). The emphasis of the BluePrint here is balanced, but there is a much greater importance placed on key aspects of learning and leadership and the way those interact in real life settings vis-à-vis the assessment center design. Following the program, individuals receive extensive feedback as well as customized career development roadmaps customized to their future destination roles, again in partnership with external resources and internal practitioners. Further, the results feed into the broader talent management and succession planning process as part of a continuous cycle, and the nuances of individual performance on leadership competencies are analyzed internally by I-O professionals to determine fit for specific roles.

Finally, the fourth checkpoint, called the Senior Leader Development Center (SLDC), represents the "top of the house" assessment suite and is focused exclusively on shaping and refining leaders for ascension to the most senior roles in the organization. For this program, the emphasis shifts to enhancing leadership capabilities that are the most critical for each leader's role and for the specific organizational context. Entry into this program is, for the most part, expected of leaders at these senior levels, and messages clearly state the need for transparency and accountability for results and for development actions in partnership with senior leadership, HR, and talent management staff. Program feedback is delivered almost exclusively by in-house I-O psychologists, given the subtleties and contextual aspects of leadership development at this level (e.g., senior vice president and above). A related but slightly different combination of custom $360^{\circ}$ feedback, personality tools, situational interviews, and a custom 8-hour simulation (in a multinational CEO role) provide the data-based insights used for coaching and individual one-on-one development with PepsiCo's internal team of I-O psychologists. As part of this process, internal resources are assigned as primary facilitators and work with an individual throughout the 18-24 month development cycle to follow up feedback efforts using a custom tool called the Development Check-In (DCI). 
By leveraging the LEF as the overlay to this entire process, PepsiCo has been able to establish a common language and set of behavioral expectations that align with the long-term success of the organization and tie directly back to the three dimension clusters of foundational, growth, and career within the BluePrint. Leadership potential within the company is determined, in large part, through validated assessments that predict success in higher level jobs. Participants at each checkpoint are administered assessments that have been designed and validated to predict success at the next higher level. For example, Checkpoint 1 participants' (Emerging Leader) potential is interpreted based on assessments that were validated to predict success at the Checkpoint 2 (Advanced Leader) level.

The validation strategy for each of the LeAD assessments was determined based on the nature of the tool and availability of resources at each checkpoint. Although criterion validation studies are extremely rare for high potential assessments, particularly at the senior-most levels of organizations, the assessments used in the first two checkpoints (Potential Leader and Emerging Leader) were criterion validated at PepsiCo. The advantage of conducting a criterion validation study in this context is the ability to empirically weight the assessments according to the differential success factors of the higher level role. The assessments used for Checkpoints 3 and 4 (Advanced Leader and Senior Leader), which rely on assessment center and immersive simulation methods, were validated using a content validation strategy.

\section{Evaluating Outcomes and Determining Organizational Impact}

Although some large and well-respected organizations have adopted the BluePrint outright, others are using it as the underlying theoretical engine for their high potential efforts. However, any organizational application stills needs to formally determine whether the tools and programs are doing what they are intended to do and are having the expected positive impact on, and acceptance within, the organization. Certainly, the criterion and content validation efforts mentioned above are an important foundation for later organizational impact. They not only provide the legal defensibility for the programs but also ensure that the assessments accurately predict an individual's likelihood of success at higher levels in the organization. This predictive capability provides important feedback for both the individual and the organization. For the individual, feedback around the BluePrint dimensions provides information on where the individual's development focus should be and where "work arounds" might be necessary (e.g., utilizing alternative behavioral approaches to the situation, or delegating to those who are more proficient in the area). For the organization, such feedback helps prioritize how often limited development dollars are appropriately invested in the talent that has the highest likelihood of progressing to the top. 
But validation efforts are not the only consideration when implementing tools and programs focused on leadership potential. In many ways, they are necessary but not sufficient for organizational impact. Validation provides the hard evidence that, for example, performance on the assessment is related to key business outcomes such as leadership retention and promotion rates. However, there are multiple levels of soft evidence that are necessary for ensuring enduring organizational impact. These include participant reactions to the assessment and feedback program, senior leader support, and cultural alignment to the BluePrint concept.

\section{Participant Reactions}

Participant reactions to assessments have been studied in a variety of contexts (e.g., Hausknecht, Day, \& Thomas, 2004). Favorable reactions have been associated with organizational justice perceptions, work performance, and commitment. When assessing for leadership potential, one could argue that the importance of ensuring highly favorable participant reactions is heightened, because an individual's career trajectory is potentially at stake. In PepsiCo's Potential Leader assessment, for example, 96\% of the participants agreed or strongly agreed with the statement, "My reaction following the feedback session was positive," and 9 months later, $83 \%$ agreed or strongly agreed with the statement, "My involvement in the program shows that the organization is invested in my growth as a leader." Further, and perhaps more important, there were no significant differences in participant reactions by potential rating (Church \& Rotolo, 2016). These results were achieved through PepsiCo's careful focus on not just the data for administrative decisions but also the entire participant experience, including developmental feedback and career planning.

\section{Relationship to Performance}

One the most desired outcomes of an assessment and development program along with an improved leadership bench is improved performance over time. Research from top development companies (Church et al., 2015) has reported that over $65 \%$ have seen moderate or better performance improvement from their formal assessment programs. Although it is still too early to examine the impact of the LeAD program on participants' long-term performance, the results obtained to date have been very encouraging. In particular, at each level of the program (Potential, Emerging, Advanced, and Senior), assessment results from participants have shown significant positive correlations with formal ratings over a 3-year window from the company's formal performance rating process. Although clearly this does not indicate a predictive relationship yet, it does speak to the design of the program and what it measures via the BluePrint and the LEF. Additional data are 
being collected (including bench metrics), which will inform future outcome analytics.

\section{Senior Leader Support}

It perhaps goes without saying that the impact of any HR program will not be realized without senior leader support. However, the key is creating such support. This is particularly true when it comes to leadership potential. Our experience suggests that every leader creates a personal subjective heuristic for what constitutes high potential from his or her perspective, and getting those leaders to focus instead on more objective tools is not an easy task. In implementing PepsiCo's LeAD program, not all of the checkpoints were implemented simultaneously. This was a conscious design decision. A topdown implementation was employed in order to first get senior leaders (a) to become familiar with the BluePrint and the concept of predicting potential and (b) to understand the value, scope, and limitations of assessment processes. Additionally, early implementation was focused more on development (versus an administrative decision-making focus) to allow for this senior leader "ramp up" familiarization period. The most widely utilized level of the LeAD program (i.e., the Potential Leader, which identifies potential in a fully transparent way) was the final checkpoint to be launched. It required significant support "on the ground" from the internal OD and HR communities, along with the I-O professionals in PepsiCo's Global Assessment and Development Center of Expertise, to ensure a successful adoption (Church \& Rotolo, 2016).

Finally, given that the LeAD architecture was developed over time, it required significant internal commitment, resources, and patience from senior leadership to design, validate, and implement. Today, all four of the LeAD programs are operating at full capacity across the global enterprise. Over 500 participants have participated in the mid-and senior-level checkpoints, and over 5,000 participants in the early professional program have been assessed and moved into the development stages. Senior leadership support for the program remains extremely strong. Moreover, the assessment and development data have been fully integrated in the company's internal talent management systems and are linked to other key aspects of talent planning and review. These include data from $\mathrm{C}$-suite critical experiences, coaching and mentoring efforts, and required leadership and functional training, as well as long-term career planning for a targeted designation role (Potential for What?). The demand for these programs from the line and HR community has significantly increased, and the data are seen as invaluable to supporting both leader development and internal talent management discussions as part of the organization's formal People Planning Process (Church \& Waclawski, 2010). Finally, there are now efforts in place to incorporate components of 
the BluePrint globally into external assessments via the "PepHire" process (PepsiCo's global professional hiring assessment) and to build interest in "2.0" versions of the existing LeAD and SLDC programs.

\section{Cultural Alignment}

Another critical component of (and indicative of) organizational impact is the alignment of leadership potential tools and programs to the culture of the organization. Although we believe that the type of tools, how they are used, and how they are implemented can be an impetus for cultural change over time, the introduction of new tools and approaches to the existing system can lead to those tools being rejected if they are not aligned with key elements of the organization's culture. This classic OD concept related to largescale change interventions (Burke, 1994) also applies to high potential talent management programs. For example, because of the focus on individual differences, leadership potential constructs align well with organizations that have a performance-based culture (such as PepsiCo). Conversely, organizations that tend to shy away from individual performance in favor of teambased systems and tools may not have the cultural features that would ensure organizational acceptance and impact.

In summary, although some discussions of organizational impact center around a program's return on investment (ROI; Cascio \& Boudreau, 2008), we prefer this more holistic approach to assessing organizational impact, which provides greater face validity and less reliance on broad financial assumptions.

\section{Lessons Learned}

On the basis of our experience with this high potential assessment and development intervention as well as others from a variety of different types of organizations, we offer a few suggestions for our fellow I-O practitioners working on similar efforts:

1. Clearly define the business need. The topic of potential identification and development has a high degree of senior leader visibility and impact on the organization's talent management system. It is vital to begin by clearly understanding and stating the business need. This includes having an understanding of senior leadership and HR perspectives on these issues while keeping in mind that they are simply perspectives and not strict rules. It is also important to understand the organization's current bench strength and depth, as well as flow or movement of current high potential pools. This will help to identify what's currently working well (or not) but also establish a baseline for later ROI analyses and will allow for a clear understanding of underlying business needs. 
2. Identify a framework of potential that is grounded in theory and research. Whether the BluePrint or another model is used in a given organizational setting, it is important to be grounded in a single and integrated framework of potential. This will guide the measurement approaches and will also help to align key stakeholders around the integrated effort. Based on our experience, this is a critical early step in the process because it establishes a clear definition of potential, which simultaneously aligns and educates organizational leaders. It is critical to note the importance of having a robust conceptual framework and not just having a definition of potential (e.g., a two level jump).

3. Develop (or transport) tools and assessments based on a rigorous job analysis or competency modeling effort. A framework such as the BluePrint provides a skeleton outline of the measurement approach. However, a set of competencies or KSAOs is also required to describe the key attributes of these future leadership levels. Only then can the appropriate assessment measures be identified and validated. There are several related considerations that also deserve a mention:

(a) Utilize a multimethod, multitrait approach (MTMM). Don't be lured by claims of a silver bullet "one assessment tells all" solution. Potential is a multifaceted construct and needs a suite of assessments to reliably measure all aspects of potential.

(b) Ensure an appropriate emphasis on foundational versus growth versus career (leadership) elements for the job level being assessed (see BluePrint model). An assessment of the potential of early career professionals should focus on a different mix of elements than an assessment of the potential of individuals later in their careers.

(c) Consider a multilevel architecture. There is considerable power in a multilevel architecture (i.e., identifying and developing high potentials at multiple organizational levels). This not only provides a broader picture of the internal talent pipeline but also can be a significant driver of culture change (e.g., sharing LIFT scores to drive organizational transparency, see Church \& Rotolo, 2016). In addition, there are useful synergies in building and validating programs at more than one level at a time.

4. Validate the process. Assessment of potential will typically be used for decision-making purposes at some point in the organization, whether for succession planning or talent movement decisions. Such decisionmaking uses are viewed by most North American and European court systems as administrative decisions that could impact an employee's career and, as such, require a demonstration of validity and job relatedness. Therefore, it is important to conduct and document validation efforts to ensure legal defensibility. 
5. Gain senior leadership support. Senior leaders need to be aligned with these efforts and, one hopes, will also be program champions. Consider using a top-down implementation approach either by having senior leaders participate in pilot assessments or by rolling out upper-level assessment efforts first before deploying similar programs lower in the organization.

6. Ensure the program design is aligned to the culture. Examine all aspects of the assessment and development program to ensure that the program aligns to the current organization culture. This includes issues related to transparency of potential rating, availability and depth of development planning resources, and data sharing with HR and senior leaders.

7. Pay attention to participant reactions for all program phases. Participant reactions should be gathered at multiple phases of the program to ensure that the program is meeting their expectations and having a positive effect on participants. This is a segment of the talent pool that must stay engaged and committed to the organization. Any perceptions of unfairness and bias or lack of face validity-no matter the empirical validity-will be detrimental to the program's acceptance, effectiveness, and impact.

8. Lay the groundwork for future ROI studies. At some point, senior leaders will ask you to demonstrate the impact and effectiveness of the program(s). It is helpful to prepare for this effort in the early stages of building the program. For example, collecting early data, such as talent movement statistics or employee career attitude data, prior to any intervention will provide the baseline data needed for a robust program evaluation later in the process.

\section{References}

Aon-Hewitt. (2013). Building the right high potential pool: How organizations define, assess, and calibrate their critical talent. Retrieved from http://www.aon.com/attachments/ human-capital-consulting/2013_Building_the_Right_High_Potential_Pool_white_paper.pdf

Burke, W. W. (1994). Organization development: A process of learning and changing (2nd ed.). Reading, MA: Addison-Wesley.

Cascio, W., \& Boudreau, J. (2008). Investing in people: Financial impact of human resource initiatives. Upper Saddle River, NJ: FT Press.

Charan, R., Carey, D., \& Useem, M. (2014). Boards that lead: When to take charge, when to partner, and when to stay out of the way. Boston, MA: Harvard Business School.

Charan, R., Drotter, S., \& Noel, J. (2001). The leadership pipeline: How to build the leadership powered company. San Francisco, CA: Jossey-Bass.

Church, A. H. (2014). What do we know about developing leadership potential? The role of OD in strategic talent management. OD Practitioner, 46(3), 52-61.

Church, A. H., \& Rotolo, C. T. (2016). Lifting the veil: What happens when you are transparent with people about their future potential? People \& Strategy, 39(4), 36-40. 
Church, A. H., Rotolo, C. T., Ginther, N. M., \& Levine, R. (2015). How are top companies designing and managing their high-potential programs? A follow-up talent management benchmark study. Consulting Psychology Journal: Practice and Research, 67(1), 17-47.

Church, A. H., \& Silzer, R. F. (2014). Going behind the corporate curtain with a blue print for leadership potential: An integrated framework for identifying high-potential talent. People and Strategy Journal, 36(4), 51-58.

Church, A. H., \& Waclawski, J. (2010). Take the Pepsi Challenge: Talent development at PepsiCo. In R. F. Silzer \& B. E. Dowell (Eds.), Strategy-driven talent management: A leadership imperative (pp. 617-640). San Francisco, CA: Jossey-Bass.

Dugan, B. A., \& O'Shea, P. G. (2014). Leadership development: Growing talent strategically. Society for Human Resource Management (SHRM) and Society for Industrial and Organizational Psychology (SIOP). Science of HR White-Paper Series. Retrieved from http://www.hrssconsultinggroup. com/uploads/6/0/6/8/60681481/shrm-siop_leader_development.pdf

Hausknecht, J. P., Day, D. V., \& Thomas, S. C. (2004). Applicant reactions to selection procedures: An updated model and meta-analysis. Personnel Psychology, 57, 639-683.

Joyce, L. W. (2010). Building the talent pipeline: Attracting and recruiting the best and the brightest. In R. F. Silzer \& B. E. Dowell (Eds.), Strategy-driven talent management: A leadership imperative (pp. 123-158). San Francisco, CA: Jossey-Bass.

MacRae, I., \& Furnham, A. (2014). High potential: How to spot, manage and develop talented people at work. London, UK: Bloomsbury.

Paese, M. J., Smith, A. B., \& Byham, W. C. (2016). Leaders ready now: Accelerating growth in a faster world. Pittsburgh, PA: Development Dimensions International Press.

Piip, J., \& Harris, R. (2014). Leadership talent identification and management. In R. Harris \& T. Short (Eds.), Workforce development: Perspectives and issues (pp. 213-231). Dordrecht, the Netherlands: Springer.

Silzer, R. F., \& Borman, W. C. (in press). The potential for leadership. In D. G. Collings, K. Mellahi, \& W. F. Cascio (Eds.), Oxford handbook of talent management. Oxford, UK: Oxford University Press.

Silzer, R., \& Church, A. H. (2009a). The pearls and perils of identifying potential. Industrial and Organizational Psychology Journal: Perspectives on Science and Practice, 2(4), 377-412.

Silzer, R. F., \& Church, A. H. (2009b). The potential for potential. Industrial and Organizational Psychology: Perspectives on Science and Practice, 2(4), 446-452.

Silzer, R. F., \& Church, A. H. (2010). Identifying and assessing high potential talent. In R. F. Silzer \& B. E. Dowell (Eds.), Strategy-driven talent management: A leadership imperative (pp. 213-280). San Francisco, CA: Jossey-Bass.

Silzer, R. F., \& Dowell, B. E. (Eds.). (2010). Strategy-driven talent management: A leadership imperative. San Francisco, CA: Jossey-Bass. 